\title{
RESEARCH PAPER \\ Differences between phenolic content and antioxidant capacity of quillay Chilean honeys and their separated phenolic extracts
}

\author{
Raquel Bridi', Gabriel Nuñez-Quijada², Patricia Aguilar ${ }^{1}$, Patricia Martínez ${ }^{1}$, \\ Eduardo Lissi $^{3}$, Ady Giordano ${ }^{1}$, Gloria Montenegro ${ }^{2}$ \\ ${ }^{1}$ Pontificia Universidad Católica de Chile, Facultad de Química. Avda Vicuña Mackenna 4860, Macul, \\ Santiago, Chile. \\ ${ }^{2}$ Pontificia Universidad Católica de Chile, Facultad de Agronomía e Ingeniería Forestal. Avda Vicuña \\ Mackenna 4860, Macul, Santiago, Chile \\ ${ }^{3}$ Universidad de Santiago de Chile, Facultad de Química y Biología. Casilla 40, Correo 33, Santiago, Chile.
}

\begin{abstract}
R. Bridi, G. Nuñez-Quijada, P. Aguilar, P. Martínez, E. Lissi, A. Giordano, and G. Montenegro. 2017. Differences between phenol content and antioxidant capacity of quillay Chilean honeys and their phenolic extracts. Cien. Inv. Agr. 44(3): 252-261. The differences between entire quillay honeys and their separated phenolic extracts in terms of phenolic content, flavonoid content and scavenging activity assessed through an Oxygen Radicals Absorbance Capacity (ORAC) assay were determined. The separated phenolic extracts of honey were obtained using Amberlite XAD-2, which is the procedure most used in analytical methods, biological assays and functional food development. The results showed that phenolic and flavonoid contents and antioxidant activity were higher in entire honeys than in their separated phenolic extracts. The recovery of phenolic acids and flavonoids was variable and depended upon the method employed. The application of polyvinylpolypyrrolidone (PVPP), a water insoluble synthetic polymer, in the separated extracts indicated an important influence of non-phenolic reducing compounds in the polyphenolic content measured by the FolinCiocalteu method. This showed the elution with methanol of these compounds together with phenolic compounds using an Amberlite XAD-2 column. The antioxidant capacity assessed through ORAC-FL and ORAC-PGR was less influenced by the interference of non-phenolic compounds than by that of total phenolic and flavonoid contents.
\end{abstract}

Keywords: Flavonoids, honey, ORAC, phenol content, phenolic extracts, Quillaja saponaria

\section{Introduction}

Chile has a great diversity of native flora that can be used by bees (Apis mellifera L.) in honey production. Quillay (Quillaja saponaria Mol, Quillajaceae) is an endemic tree of Chile (Re-

Received February 28, 2017. Accepted November 11, 2017. Corresponding author: rbridi@uc.cl gions IV to IX) with flowers that are very attractive to bees (Montenegro et al., 2009). Quillaja saponaria is one of the most emblematic flower honeys from Chile, both for its abundance and sensory characteristics (Montenegro et al., 2008). The antioxidant and antimicrobial activities of Chilean honey have been studied in the last few years with excellent results. These activities 
are primarily attributed to phenolic compounds such as flavonoids (Montenegro et al., 2009; 2013). Epidemiological evidence indicates that the consumption of foods containing phenolic compounds is inversely associated with the risk of developing several oxidative stress-related pathophysiological conditions (Vauzour et al., 2010). Furthermore, some studies demonstrate a strong correlation between the antioxidant activity of honey and the total phenolic content (Gheldof and Engeseth, 2002; Montenegro et al., 2013; Pontis et al., 2014).

Chemically, honey is a highly concentrated solution of a complex mixture of sugars, predominantly fructose and glucose, with sucrose, maltose, and many other sugars at much lower concentrations. In addition to sugars, honey also contains small amounts of minerals, proteins, vitamins, and organic acids. The composition of phenolic compounds depends strongly on the plant species from which the nectar was collected (Iurlina et al., 2009; Biesaga and Pyrzyńska, 2013). Furthermore, the resulting honey is also influenced by others factors, such as environmental conditions and climate (Iurlina et al., 2009; Pyrzynska and Biesaga, 2009; Montenegro et al., 2013).

Procedures using Amberlite XAD-2 columns for cleaning complex matrices such as honey and isolating phenolic compounds are often performed. In some cases, this step reduces the requirement for sample manipulation and produces a sample extract that is uniformly enriched in all components of interest and is free from undesired matrix components. In these procedures, aqueous, acidified honey solutions are passed through the columns to retain phenolic compounds in sorbent beds and are afterward eluded with methanol (Tura and Robards, 2002; Gómez-Caravaca et al., 2006). The aqueous cleaning process during Amberlite XAD-2 extraction can remove sugars and other polar compounds, including glycosylated phenolic compounds, which can also contribute to the antioxidant capacity of honey. Therefore, when comparing honey and the extract, considerable changes in antioxidant activity and phenolic compounds may result. As previously demonstrated, honeys and their extracts can have different antioxidant properties (Ferreira et al., 2009). However, the differences of total phenolic and flavonoid content and Oxygen Radicals Absorbance Capacity index (ORAC) between entire honeys and their separated phenolic extracts have not been reported. The ORAC method is currently used for foods and is based on the ability to trap AAPH-derived radicals, which is correlated with the antioxidant capacity of complex samples (Dorta et al., 2015). The pretreatment of phenolic-rich matrices with polyvinylpolypyrrolidone (PVPP), a water insoluble synthetic polymer, is described as an efficient way to discriminate between phenolics and non-phenolic reducing compounds when using the Folin-Ciocalteu (FC) assay to assess total phenolic content in complex matrices (Bridi et al., 2014).

The present study analyzes the difference between entire honeys from quillay and their separated phenolic extracts using Amberlite XAD-2 columns. The differences measured here are in terms of content of total phenolics (TP) determined by the FC method using PVPP; content of flavonoids; and scavenging activity assessed through the ORAC assay using fluorescein (ORAC-FL) and pyrogallol red (ORAC-PGR) as probes.

\section{Materials and methods}

\section{Chemicals}

6-Hydroxy-2,5,8-tetramethylchroman-2-carboxylic acid (Trolox), pyrogallol-red (PGR), 2,2'-Azobis(2-amidinopropane) dihydrochloride (AAPH) and all the antioxidants studied were purchased from Sigma-Aldrich (St. Louis, Mo., U.S.A.). Merck (Darmstadt, Germany) supplied the Folin-Ciocalteu's phenol reagent $(2 \mathrm{~N})$, aluminum chloride, sodium chloride, hydrochloridric acid, disodium hydrogen phosphate dihydrate, and sodium phosphate monobasic reagent. Water was 
purified in a Milli-Q system (Synergy; Millipore, Darmstadt, Germany).

\section{Honey collection}

Honeys were obtained from apiaries located in region VI, Chile. The botanical origin of the honeys (percentage of $Q$. saponaria) was determined according to Chilean regulation (Montenegro et al., 2008). Twenty grams of honey was diluted in $20 \mathrm{~mL}$ of distilled water and centrifuged at $2,500 \mathrm{rpm}$ for 5 minutes. The supernatant was eliminated, and the pelleted pollen was analyzed using optical microscopy. The pollen grains from each sample were identified using the palinoteque and reference bibliography (Montenegro and Timmermann, 2002). Five preparations from each honey sample were analyzed.

\section{Phenolic extracts}

Phenolic extracts of the honeys were prepared following the methodology of Montenegro et al. (Montenegro et al., 2009; Montenegro and Ortega, 2011). Honey $(50 \mathrm{~g})$ was diluted with water at $\mathrm{pH}$ $2(\mathrm{HCl})$ to a final volume of $250 \mathrm{~mL}$. The solution was transferred to an Amberlite XAD-2 resin column (250 mm height x $20 \mathrm{~mm}$ diameter) and then was eluted with $100 \mathrm{~mL}$ of acidified water ( $\mathrm{HCl}, \mathrm{pH} 2)$, with $200 \mathrm{~mL}$ of distilled water, and finally with $300 \mathrm{~mL}$ of pure methanol. The methanolic fraction was evaporated to dryness in a rotary evaporator at $45^{\circ} \mathrm{C}$. The residue was re-suspended in $4 \mathrm{~mL}$ of methanol, filtered and stored at $-20{ }^{\circ} \mathrm{C}$ in the dark until use.

\section{Total phenolic determination}

The total content of phenols (TP) was determined according to the Folin-Ciocalteu (FC) method (Singleton et al., 1999). A volume of $500 \mu \mathrm{L}$ of diluted solution of phenolic extract or honey sample diluted in water $(0.2 \mathrm{~g}$ of honey to $4 \mathrm{~mL}$ of water) was mixed with $2.0 \mathrm{~mL}$ of the $\mathrm{FC}$ reagent $1: 10(\mathrm{v} / \mathrm{v})$ and $1.2 \mathrm{~mL}$ of a solution of $\mathrm{Na}_{2} \mathrm{CO}_{3}$. After 60 minutes at room temperature in the dark, the absorbance of the resulting blue solution was measured at $760 \mathrm{~nm}$ using an Agilent 8453 UV-visible spectrophotometer (Palo Alto, Calif., U.S.A.). Quantification was performed by a linear regression from a calibration curve constructed with gallic acid ( 5 to $50 \mu \mathrm{M}$ ). Results are expressed as milligrams of gallic acid equivalents per 100 grams of honey (mg GAE $100 \mathrm{~g}^{-1}$ honey). Values are reported as the mean \pm standard deviation (SD) of 3 independent determinations.

The effect of the polyvinylpolypyrrolidone (PVPP) treatment on the total phenolic content of the sample (entire honey and phenolic extract) was measured according to Bridi et al. (Bridi et al., 2014) (Eq. 1):

$\mathrm{FC}_{\mathrm{XH}}=\mathrm{FC}_{\text {тот }}-\mathrm{FC}_{\mathrm{PVPP}}$

where

$\mathrm{FC}_{\mathrm{XH}}=\mathrm{FC}$ value for polyphenols

$\mathrm{FC}_{\text {тот }}=\mathrm{FC}$ without PVPP pretreatment

$\mathrm{FC}_{\text {PVPP }}=\mathrm{FC}$ non-polyphenolic compounds (PVPP pretreatment)

The pretreatment of complex samples with PVPP allows the efficient separation of polyphenols and non-polyphenolic reducing derivatives (i.e., sugars, ascorbic acid, and sulfite) from the original matrix. This PVPP-based procedure allows for the evaluation of total phenolic content through FC methodology without the contribution of nonphenolic reducing compounds.

\section{Flavonoids determination}

Flavonoid content was estimated using an aluminum chloride method based on the procedure described by Woisky and Salatino (1998). A volume 
of $500 \mu \mathrm{L}$ of honey sample diluted in water $(0.1 \mathrm{~g}$ of honey to $1.6 \mathrm{~mL}$ of water) or diluted solutions of phenolic extracts were mixed with $500 \mu \mathrm{L}$ of $2 \% \mathrm{AlCl}_{3}$ ethanol solution. After 60 minutes at room temperature, the absorbance was measured at $420 \mathrm{~nm}$ using an Agilent $8453 \mathrm{UV}$-visible spectrophotometer (Palo Alto, Calif., U.S.A.). Total flavonoid content was calculated as milligrams of quercetin equivalents per 100 grams of honey (QE $100 \mathrm{~g}^{-1}$ honey) from a calibration curve (5 to $30 \mu \mathrm{M}$ quercetin). Values are reported as the mean $\pm \mathrm{SD}$ of 3 independent determinations.

\section{ORAC (Oxygen Radical Absorbance Capacity) determinations}

The consumption of FL or PGR, associated with the incubation with AAPH, was estimated from fluorescence $(F)$ or absorbance $(A)$ measurements, respectively. Values of $(F / F 0)$ or $(A / A 0)$ were plotted as a function of time. Integration of the area under the curve (AUC) was performed up to a time such that $\left(F / F_{0}\right)$ or $\left(A / A_{0}\right)$ was ca. 0.2. These areas were employed to obtain ORAC values, according to Eq. (2):

$$
O R A C=\frac{\left(A U C-A U C_{0}\right)}{\left(A U C_{\text {Trolox }}-A U C_{0}\right)} f[\text { Trolox }]
$$

where AUC is the area under the curve in the presence of the sample, integrated between time zero and the time corresponding to $80 \%$ of probe consumption; $\mathrm{AUC}_{0}$ is the area under the curve in the control (without antioxidant); $\mathrm{AUC}_{\text {Trolox }}$ is the area under the curve for Trolox; $f$ is the dilution factor of the sample, equal to the ratio between the total volume of the AAPH-FL or AAPH-PGR solution and the added sample volume; [Trolox] is the Trolox molar concentration (López-Alarcón and Lissi, 2006). Results are expressed as $\mathrm{mM}$ equivalents of Trolox (TE) per gram of honey (TE/g). Values are reported as the mean $\pm \mathrm{SD}$ of 3 independent determinations.

\section{Statistical analyses}

The assays were conducted in triplicate, and the results are given as mean values and their standard deviations (SD). Statistical analyses were performed using Student's unpaired $t$-tests and Pearson parametric correlations. A value of $\mathrm{p}<0.05$ was considered significant.

\section{Results and discussion}

Chile produces a limited number of monofloral honeys of native plant origin. The monofloral honeys produced in the central zone are primarily derived from quillay (Montenegro et al., 2008; 2009). Given their excellent qualities, these honeys are highly appreciated in the international market and generate greater returns than non-differentiated honeys. Currently, honey is used for a variety of purposes, including as food, a food ingredient, and an ingredient in native medicine-like products. The beneficial health effects associated with honey are assigned, at least partially, to the richness in polyphenols.

\section{Characterization of honey samples}

The ten quillay honey samples examined were collected in region VI of Chile. The botanical origin was determined by micro-morphological analysis of pollen grains and other structures therein. In Chile, the official policy (NCh2981. Of2005) established by the Standards Division of the National Institute for Standardization [2] classifies the honeys as monofloral, bifloral, or polyfloral according to their botanical origins. Monofloral honeys are those in which at least $45 \%$ or more of the pollen grains belong to the same species; bifloral honeys are those in which pollen grains from two species are dominant within the total pollen grains; and polyfloral honeys are those in which none of the requirements for monofloral and bifloral honeys are met. The quillay pollen percentage of the samples is given in Table 1 . 
Table 1. Total phenolic content (TP) in honey and separated phenolic extracts.

\begin{tabular}{|c|c|c|c|c|c|}
\hline \multirow[b]{2}{*}{ Sample } & \multirow{2}{*}{$\begin{array}{l}\text { \% Pollen } \\
\text { quillay }\end{array}$} & \multicolumn{2}{|c|}{ Honey } & \multicolumn{2}{|c|}{ Separated phenolic extracts } \\
\hline & & $\begin{array}{c}\mathrm{TP} \\
\left(\mathrm{FC}_{\text {TOTAL }}\right)\end{array}$ & $\begin{array}{l}\mathrm{TP}_{(\mathrm{PVPP})} \\
\left(\mathrm{FC}_{\mathrm{XH}}\right)\end{array}$ & $\begin{array}{c}\mathrm{TP} \\
\left(\mathrm{FC}_{\text {TOTAL }}\right)\end{array}$ & $\begin{array}{l}\mathrm{TP}_{(\mathrm{PVPP})} \\
\left(\mathrm{FC}_{\mathrm{XH}}\right)\end{array}$ \\
\hline 1 & 35 & $50.9 \pm 0.68$ & $36.9 \pm 0.45^{\#}$ & $13.70 \pm 0.36^{*}$ & $6.96 \pm 0.16^{\#}$ \\
\hline 2 & 39 & $57.8 \pm 0.97$ & $39.4 \pm 0.63^{\#}$ & $12.94 \pm 0.03 *$ & $7.89 \pm 0.07^{\sharp}$ \\
\hline 3 & 46 & $52.2 \pm 0.55$ & $23.8 \pm 0.55^{\#}$ & $16.93 \pm 0.66^{*}$ & $9.12 \pm 0.3^{\#}$ \\
\hline 4 & 47 & $56.6 \pm 0.25$ & $43.7 \pm 0.25^{\#}$ & $13.02 \pm 0.71 *$ & $6.07 \pm 0.49^{\#}$ \\
\hline 5 & 47 & $64.8 \pm 0.71$ & $37.1 \pm 0.87^{\#}$ & $12.65 \pm 0.04 *$ & $7.12 \pm 0.29$ \\
\hline 6 & 48 & $59.1 \pm 0.48$ & $42.2 \pm 0.35^{\#}$ & $10.48 \pm 1.59 *$ & $5.33 \pm 0.06^{\#}$ \\
\hline 7 & 50 & $54.8 \pm 0.62$ & $44.9 \pm 0.42^{\#}$ & $12.66 \pm 0.58 *$ & $6.34 \pm 0.39^{\#}$ \\
\hline 8 & 51 & $44.7 \pm 0.57$ & $33.9 \pm 0.91^{\#}$ & $14.02 \pm 1.06^{*}$ & $7.81 \pm 0.60^{\#}$ \\
\hline 9 & 68 & $57.8 \pm 0.97$ & $35.1 \pm 0.64^{\#}$ & $12.08 \pm 0.90^{*}$ & $7.34 \pm 0.19^{\#}$ \\
\hline 10 & 70 & $52.0 \pm 0.40$ & $41.7 \pm 0.76^{\#}$ & $11.72 \pm 1.27^{*}$ & $7.81 \pm 0.21^{\#}$ \\
\hline
\end{tabular}

Results expressed in (mg GAE $100 \mathrm{~g}^{-1}$ honey). Values represent the mean $\pm \mathrm{SD}$ for three independent experiments performed in triplicate. The lowest and highest polyphenol contents are shown in bold. $\mathrm{FC}_{\text {TOTAL }}$ (Folin-Ciocalteu without PVPP pretreatment); $\mathrm{FC}_{\mathrm{XH}}$ (value for polyphenols, with PVPP treatment). Data were analyzed by Student's unpaired $t$-tests. *Different from honey without PVPP pretreatment $(\mathrm{p}<0.001)$. ${ }^{\#}$ Different from respective sample without PVPP pretreatment $(\mathrm{p}<0.001)$.

According to the classification, samples 1 and 2 were multifloral honeys, with a predominance of Q. saponaria at $35 \%$ and $39 \%$, respectively. Samples 3 to 10 were monofloral honeys from Quillaja saponaria because they had more than $45 \%$ pollen grain from this species (Montenegro et al., 2008). In these samples, the relative percentages of quillay pollen grains varied from $46 \%$ to $71 \%$. Generally, monofloral honeys have higher economic value than multifloral honeys because their sensorial properties (aroma, color and taste) and nutritive characteristics are more consistent over time (Vauzour et al., 2010). The pollen showed a high diversity of species, highlighting the large contributions of introduced species such as Galega officinalis (galega), Medicago sativa (alfalfa), Trifolium repens (white clover) and Brassica sp. (cabbage, cauliflower, broccoli, Brussels sprout). By contrast, low percentages of endemic species of Chile such as Lithraea caustic (litre) and Retanilla trinervia were observed.

Separated phenolic extracts of honey were obtained using Amberlite XAD-2 columns, and the columns cleaned the complex matrices of honey and concentrated the phenolic compounds using a methodology described by Montenegro and Ortega (Montenegro and Ortega, 2011). These extracts are widely preferred to entire honeys in analytical methods, biological assays and functional food development. This preference is because the sugars that give entire honeys a syrupy texture cause difficulties for some analyses and preparations (Ferreira et al., 2009). The differences between quillay honeys and their phenolic extracts concerning polyphenolic compounds and ORAC indexes were also estimated (for procedure details see Figure 1).

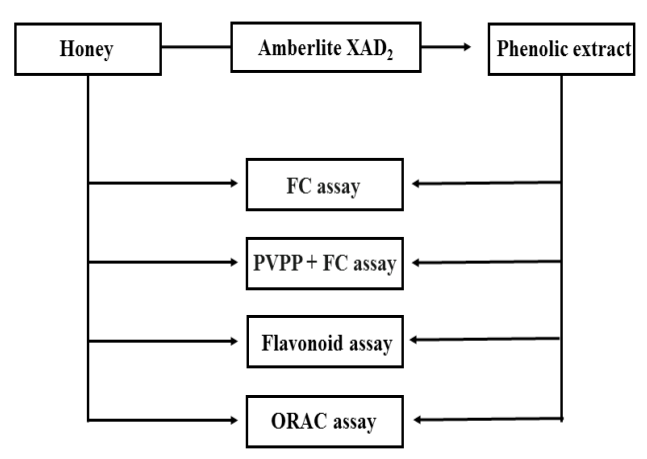

Figure 1. Scheme of experimental evaluations for honey and phenolic extracts. 
Table 1 shows the total phenolic content of honey and phenolic extracts obtained using Amberlite XAD-2. The phenolic content was significantly

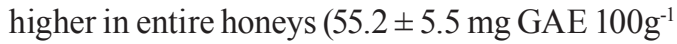
honey) than in their separated phenolic extracts

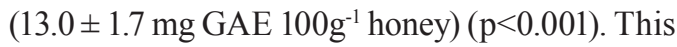
result was observed for both multifloral (samples 1 and 2) and monofloral honeys (samples 3 to 10). As commented previously, entire honey contains some non-phenolic reducing compounds that can lead to an increase in the absorbance values and to positive errors in the determination of phenolic compounds by the FC method. In the presence of PVPP, an agent employed to separate phenolics and non-phenolic reducing compounds (i.e., sugars, ascorbic acid, and sulfite), the values of phenolic compounds $\left(\mathrm{FC}_{\mathrm{XH}}\right)$ were $37.9 \pm 6.2 \mathrm{mg}$ GAE $100 \mathrm{~g}^{-1}$

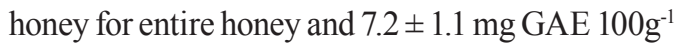
honey for extracts, using Equation 1. Therefore, applying the PVPP pretreatment allowed for the estimation of non-phenolic reducing compounds. In entire honey, the non-phenolic compounds ranged from $18.1 \%$ to $54.7 \%$ and in phenolic extracts, between $33.3 \%$ and $53.3 \%$. These results indicated an important influence of non-reducing compounds in the polyphenolic content measured by the FC method. The FC assay has been widely used to estimate the polyphenolic content of food and beverage matrixes (Bridi et al., 2014). In fact, reductive sugars (such as fructose, glucose, and sucrose), organic acids (such as ascorbic, citric, and tartaric acids), ferrous sulfate, and sodium sulfite are all potentially capable of interfering with the assessment of phenolic compounds in food matrixes by the FC assay (Lester et al., 2012; Bridi et al., 2014). A study using an HPLC (high performance liquid chromatography) technique showed that the honey phenolic fraction obtained with the Amberlite XAD-2 column contains some of the flavonoids previously reported for honey. However, the HPLC flavonoid peaks were contaminated with other non-flavonoid phenols. Additionally, although many sugars were eliminated by including an Amberlite XAD-2 step, some sugars continued to contaminate the phenolic fraction, which was eluted with methanol
(Ferreres et al., 1994). These results could explain the large percentage of interference present in the separated extracts analyzed. Figure 2 shows the comparison of flavonoid content of honey samples and their separated phenolic extracts. Significantly higher flavonoid content was observed in the entire samples $\left(9.6 \pm 1.5 \mathrm{QE} 100 \mathrm{~g}^{-1}\right.$ honey) than in their phenolic extracts $(2.2 \pm 0.4$ QE $100 \mathrm{~g}^{-1}$ honey) using the aluminum chloride method $(p<0.001)$ (Woisky and Salatino, 1998).

Further, with the results obtained, we calculated the recovery of phenolic compounds with Amberlite XAD-2. For this calculation, phenolic compound values using the FC method obtained after PVPP treatment were used. The average recovery of phenolic compounds was $20 \pm 7 \%$, whereas the average flavonoid recovery was $23 \pm 5 \%$ using the aluminum chloride method. This low recovery might be due to the chemical composition of the studied honeys, which would directly influence the extraction of these compounds (Pyrzynska and Biesaga, 2009). The fractionation of honey on a XAD-2 column is the most commonly used in published studies. Recoveries of phenolic acids and flavonoids extracted from deionized water $(\mathrm{pH}$ 2) using Amberlite XAD-2 report different recovery percentages, most likely depending

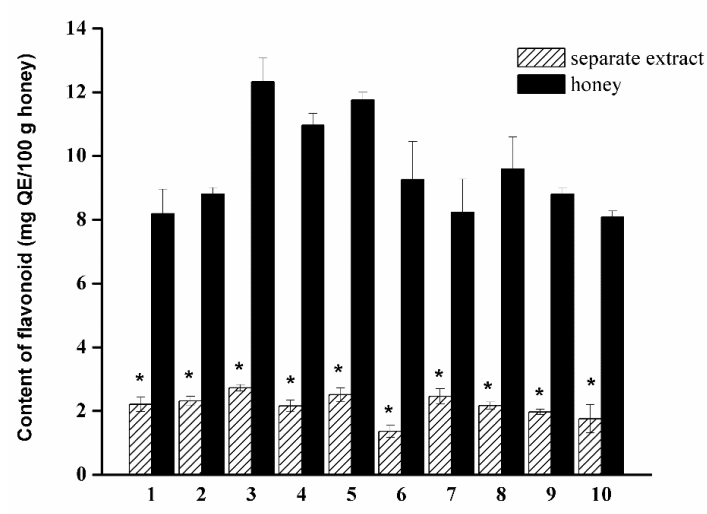

Figure 2. Content of flavonoid compounds (mg QE 100 g-1 honey) obtained in the separated phenolic extracts and entire honey samples. Values represent the mean \pm SD for three independent experiments performed in triplicate. * Different from respective honey by Student's unpaired t-test $(\mathrm{p}<0.001)$. 
on the characteristics of the molecules studied. Kaempferol, $p$-coumaric acid and syringic acid are completely adsorbed, but the recovery of gallic acid, caffeic acid and quercetin by methanol is much less efficient, e.g., only 54\% for quercetin (Michalkiewicz et al., 2008; Pyrzynska and Biesaga, 2009; Montenegro et al., 2013). Therefore, the qualitative and quantitative difference in phenolic contents of honey reported in several studies can be due to, at least partially, differences in extraction efficiency. Previous studies of quillay honey conducted by our investigation group showed the presence of compounds such as chlorogenic acid, caffeic acid, syringic acid, p-coumaric acid, gallic acid, quercetin, rutin and naringenin (Montenegro et al., 2009; 2013).

Scavenging activity toward peroxyl/alkoxyl radicals (ORAC assay)

We studied the antioxidant capacity of the phenolic extracts and entire honey samples using ORAC methodology. For this purpose, we employed fluorescein (ORAC-FL) and pyrogallol red (ORACPGR) as probes. The ORAC index is related to the amount and reactivity of a given phenolic compound toward the free radicals generated in the AAPH (2,2'-azo-bis(2-amidinopropane) dihydrochloride) thermolysis (López-Alarcón and Lissi, 2006). This index is used as a measure of the capacity of a sample to remove peroxyl and/ or alkoxyl radicals. In complex mixtures, the concentration, chemical nature, and possibly the interaction among the antioxidants in a sample determine this index (Dorta et al., 2015).

Figure 3 shows medians, inter-quartile ranges and the maximum and minimum ORAC-FL (A) and ORAC-PGR (B) values between entire honeys and their respective phenolic extracts. Statistical analyses indicated differences $(\mathrm{p}<0.05)$ between ORAC-FL values obtained for entire samples $\left(3.9 \pm 1.4 \mu \mathrm{M} \mathrm{TE} \mathrm{g}^{-1}\right.$ honey) and their separated phenolic extracts $\left(2.6 \pm 0.6 \mu \mathrm{M} \mathrm{TE} \mathrm{g}^{-1}\right.$ honey). A difference was also shown $(\mathrm{p}<0.001)$ between
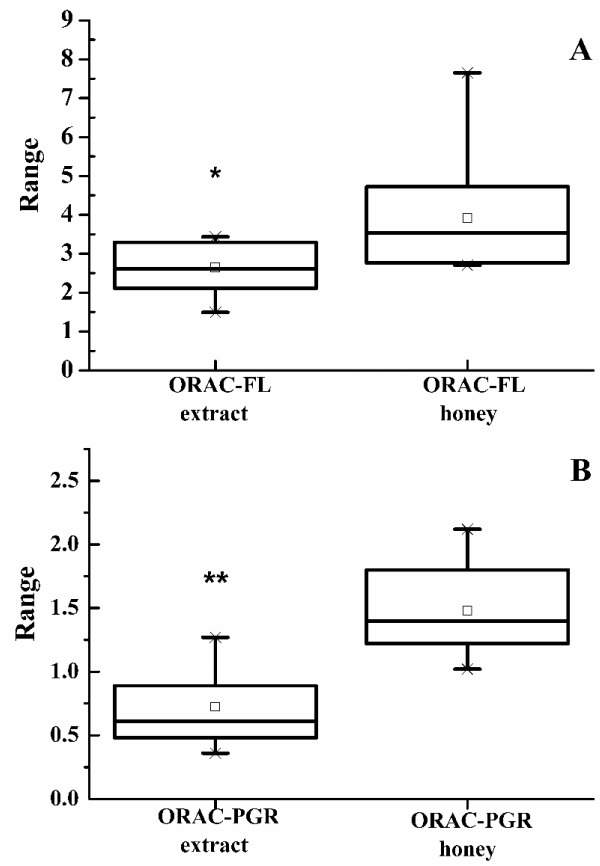

Figure 3. Box plots of the ORAC-FL (A) and ORAC-PGR (B) values of separated phenolic extracts and entire honeys. Horizontal lines within boxes are medians, boxes show inter-quartile ranges and bars show the maximum and minimum values. Different from honey by Student's t-test: $*(\mathrm{p}<0.05), * *(\mathrm{p}<0.001)$.

ORAC-PGR values for entire samples $(1.5 \pm 0.4$ $\mu \mathrm{M} \mathrm{TE} \mathrm{g}^{-1}$ honey) and the phenolic extracts $(0.72$ $\pm 0.3 \mu \mathrm{M} \mathrm{TE} \mathrm{g}^{-1}$ honey). The larger ORAC-FL and ORAC-PGR indexes shown by honeys than by their extracts indicated that other substances with antioxidant potential were lost in the extraction process. In this regard, an assay using three Portuguese honey samples shows that the reducing power is higher for the entire honeys than for the phenolic extracts. This indicates that in this case, sugars and other compounds in the entire honey may have good reducing capacity (Ferreira et al., 2009).

Correlations between the percentage of quillay pollen in the samples and all the parameters studied were analyzed. No significant correlations were found between the percentage of quillay pollen, which varied between $35 \%$ and $71 \%$, and phenolic content, flavonoid content, or antioxidant capacity as determined by the ORAC method for either entire honeys or the respective extracts. This result 
indicated an important participation of minor vegetal species to the contribution of phenolic compounds and substances with antioxidant capacity. Additionally, no correlation was found between the total phenolic and flavonoid contents in the entire quillay honey and the ORAC values. By contrast, a strong and significant correlation was found between flavonoids and ORAC-FL ( 0.63 ; $\mathrm{p}<0.05)$ and between flavonoids and ORAC-PGR $(0.68 ; \mathrm{p}<0.05)$ values for the separated phenolic extracts. Similar results were reported by Ferreira et al. (2009) who detected a high correlation coefficient between phenolic content and the scavenging activity by DPPH for phenolic extracts (Ferreira et al., 2009). Additionally, according to the authors, this result indicates that this effect is more easily observed in the phenolic extracts than in the entire honey. This could be because compounds in phenolic extracts are structurally related and have similar biological properties. Despite this, the results suggested that the interference of non-phenolic compounds on the ORAC index was less than that on values of phenolic and flavonoid compounds. This result would explain why in some cases the differences between ORAC values of entire honey and extracts were small. For quillay honey, the results of this study indicated that important differences existed in entire honey and its separated extract obtained from Amberlite XAD-2. The phenolic content, flavonoid content, and antioxidant capacity were significantly greater in entire honeys than in their extracts.

The main conclusions are as follows. The total phenolic content (TP) determined by the FC assay, the flavonoid content, and the ORAC index were higher in the entire quillay honey samples than in the separated phenolic extracts. The extracts were obtained after separation with Amberlite XAD-2 and elution with methanol. Despite the widespread use of this extraction technique, we observed that the recoveries of phenolic acids and flavonoids were variable and depended upon the evaluated parameter. Furthermore, the application of PVPP pretreatment in the separated extracts indicated an important influence of non-phenolic reducing compounds in the polyphenolic content measured by the FC method. This indicated the elution with methanol of these compounds together with phenolic compounds using Amberlite XAD2. The antioxidant capacity assessed through ORAC-FL and ORAC-PGR was less influenced by the interference of non-phenolic compounds than TP and flavonoid values.

\section{Acknowledgments}

VRI Interdisciplina (\#31/2013) and FIC (\#301263950) supported this work.

\section{Resumen}

R. Bridi, G. Nuñez-Quijada, P. Aguilar, P. Martínez, E. Lissi, A. Giordano, y G. Montenegro. 2017. Diferencia entre el contenido de compuestos fenólicos y la capacidad antioxidante de mieles chilenas de quillay y sus extractos fenólicos separados. Cien. Inv. Agr. 44(3): 252-261. Se estudió la diferencia entre miel de quillay entera y sus extractos fenólicos en función del contenido de compuestos fenólicos totales, flavonoides y de la actividad antioxidante mediante el ensayo de la Capacidad de Absorción de Radicales de Oxígeno (ORAC). Los extractos fenólicos se obtuvieron utilizando columna de Amberlite XAD-2, procedimiento muy empleado en estudios analíticos, biológicos y en el desarrollo de alimentos funcionales. Los resultados demostraran que el contenido de fenoles totales, flavonoides y la capacidad antioxidante son mayores en las mieles enteras que en sus extractos fenólicos separados. Sin embargo, la recuperación de ácidos fenólicos y flavonoides es variable y depende de la metodología empleada. La aplicación de polivinilpolipirrolidona (PVPP), 
un polímero sintético insoluble en agua, en los extractos separados indicó una importante influencia de compuestos reductores no fenólicos en la medida de fenoles totales determinada por el método de Folin-Ciocalteu. Esto demuestra que utilizando columna Amberlite XAD-2 compuestos no-fenólicos son eluídos con metanol conjuntamente los fenoles. La capacidad antioxidante medida por ORAC es menos influenciada por la contribución de compuestos no fenólicos que los valores de fenoles totales obtenidos por el método FC.

Palabras clave: Extractos fenólicos, fenoles totales, determinada, flavonoides, miel, ORAC, Quillaja saponaria.

\section{References}

Biesaga M., and K. Pyrzyńska. 2013 Stability of bioactive polyphenols from honey during different extraction methods. Food Chem 136:46-54.

Bridi R., M.J. Troncoso, C. Folch-Cano, J. Fuentes, H. Speisky, and C. López-Alarcón. 2014. A Polyvinylpolypyrrolidone (PVPP)-Assisted FolinCiocalteu Assay to Assess Total Phenol Content of Commercial Beverages. Food Anal Methods 7:2075-2083.

Dorta E., E. Fuentes-Lemus, A. Aspee, E. Atala, H. Speisky, R. Bridi, E. Lissi, and C. Lopez-Alarcon. 2015. The ORAC (oxygen radical absorbance capacity) index does not reflect the capacity of antioxidants to trap peroxyl radicals. RSC Advances 5:39899-39902.

Ferreira I.C.F.R., E. Aires, J.C.M. Barreira, and L.M. Estevinho. 2009. Antioxidant activity of Portuguese honey samples: Different contributions of the entire honey and phenolic extract. Food Chem 114:1438-1443.

Ferreres F., F.A. Tomás-Barberán, C. Soler, C. García-Viguera, A. Ortiz, and F. Tomás-Lorente. 1994. A simple extractive technique for honey flavonoid HPLC analysis. Apidologie 25:21-30.

Gheldof N., and N.J. Engeseth. 2002. Antioxidant Capacity of Honeys from Various Floral Sources Based on the Determination of Oxygen Radical Absorbance Capacity and Inhibition of in Vitro Lipoprotein Oxidation in Human Serum Samples. J. Agric. Food Chem. 50:3050-3055.

Gómez-Caravaca A.M., M. Gómez-Romero, D. Arráez-Román, A. Segura-Carretero, and A. Fernández-Gutiérrez. 2006. Advances in the analysis of phenolic compounds in products de- rived from bees. J Pharm Biomed Anal 41:12201234.

Iurlina M.O., A.I. Saiz, R. Fritz, and G.D. Manrique. (2009) Major flavonoids of Argentinean honeys. Optimisation of the extraction method and analysis of their content in relationship to the geographical source of honeys. Food Chem 115:1141-1149.

Lester G.E., K.S. Lewers, M.B. Medina, and R.A. Saftner. 2012. Comparative analysis of strawberry total phenolics via Fast Blue BB vs. FolinCiocalteu: Assay interference by ascorbic acid. J Food Compost Anal 27:102-107.

López-Alarcón C., and E. Lissi. 2006. A novel and simple ORAC methodology based on the interaction of Pyrogallol Red with peroxyl radicals. Free Radic. Res. 40:979-985.

Michalkiewicz A., M. Biesaga, and K. Pyrzynska. 2008. Solid-phase extraction procedure for determination of phenolic acids and some flavonols in honey. J Chromatogr A 1187:18-24.

Montenegro G., J. Díaz-Forestier, C. Fredes, and S. Rodríguez. 2013. Phenolic profiles of nectar and honey of Quillaja saponaria Mol. (Quillajaceae) as potential chemical markers. Biological Research 46:177-182.

Montenegro G., M. Gómez, J. Díaz-Forestier, and R. Pizarro. 2008. Aplicación de la Norma Chilena Oficial de denominación de origen botánico de la miel para la caracterización de la producción apícola. Cien. Inv. Agr. 35:181-190.

Montenegro G., F. Salas, R.C. Pena, and R. Pizarro. 2009. Antibacterial and antifungic activity of the unifloral honeys of Quillaja saponaria, an endemic Chilean species. Phyton-International Journal of Experimental Botany 78:141-146. 
Montenegro G., and B.N. Timmermann. 2002. Chile nuestra flora útil: guía de plantas de uso apícola, en medicina folklórica, artesanal y ornamental Ediciones Universidad Católica de Chile, Santiago.

Montenegro R.G., and F.X.A. Ortega. 2011. Uses of unifloral ulmo honey extract as a bactericide and a fungicide, in: P.U.C. d. Chile (Ed.), Google Patents, Chile.

Pontis J.A., L.A.M.A.d. Costa, S.J.R.d. Silva, and A. Flach. 2014. Color, phenolic and flavonoid content, and antioxidant activity of honey from Roraima, Brazil. Food Science and Technology (Campinas) 34:69-73.

Pyrzynska K., and M. Biesaga. 2009. Analysis of phenolic acids and flavonoids in honey. Trends Analyt Chem 28:893-902.
Singleton V., R. Orthofer, and R. Lamuela-Raventos. 1999. Analysis of total phenols and other oxidation substrates and antioxidants by means of Folin-Ciocalteau reagent. Meth. Enzymol. 299:152-178.

Tura D., and K. Robards. (2002) Sample handling strategies for the determination of biophenols in food and plants. J Chromatogr A 975:71-93.

Vauzour D., A. Rodriguez-Mateos, G. Corona, M.J. Oruna-Concha, and J.P.E. Spencer. 2010. Polyphenols and Human Health: Prevention of Disease and Mechanisms of Action. Nutrients 2:1106-1131.

Woisky R.G., and A. Salatino. 1998. Analysis of propolis: some parameters and procedures for chemical quality control. J. Apic. Res. 37:99105 . 